\title{
Review Paper: Paying Attention to Circadian Rhythms in the Treatment of COVID-19
}

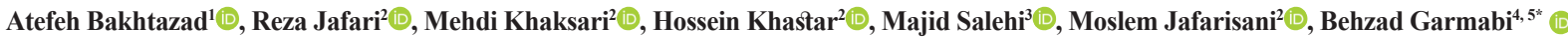

1. Cellular and Molecular Research Center, Iran University of Medical Sciences, Tehran, Iran.

2. School of Medicine, Shahroud University of Medical Sciences, Shahroud, Iran.

3. Department of Tissue Engineering, School of Medicine, Shahroud University of Medical Sciences, Shahroud, Iran

4. Center for Health Related Social and Behavioral Sciences Research, Shahroud University of Medical Sciences, Shahroud, Iran.

5. Study and Treatment of Circadian Rhythms Research Center, Shahroud University of Medical Sciences, Shahroud, Iran.

\begin{tabular}{|c|c|}
\hline $\begin{array}{l}\text { Use vour device to scan } \\
\text { and read the article online }\end{array}$ & \\
\hline arpa & $\begin{array}{l}\text { Circadian Rhythms in the Treatment of COVID-19. Basic and Clinical Neuroscience, 11(3.Covid19), 233-246. http://dx.doi. } \\
\text { org/10.32598/bcn.11.covid19.2584.1 }\end{array}$ \\
\hline 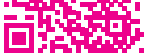 & dol' http://dx.doi.org/10.32598/ben.11.covid19.2584.1 \\
\hline
\end{tabular}

\section{(c) (1) (5)}

Article info:

Received: 19 May 2020

First Revision: 25 May 2020

Accepted: 27 Jun 2020

Available Online: 22 Jun 2020

Keywords:

Circadian rhythm, Coronavirus disease 2019 (COVID-19), Clock genes, Melatonin, Angiotensin-converting enzyme

\begin{abstract}
$\underline{\text { A B S T RA C T }}$
The bidirectional association between the circadian system and innate-adaptive immune functions has been highlighted in many investigations. Viruses are a submicroscopic infectious agent that activate the immune system after entering the human host cell. A novel virus, socalled Coronavirus Disease 2019 (COVID-19), which has recently emerged, is an infectious disease caused by Severe Acute Respiratory Syndrome Coronavirus 2 (SARS-CoV-2). Previous investigations show that the factors that are strongly controlled by circadian rhythms, such as clock genes and melatonin, modulate the immune response and may, therefore, influence the healing processes of COVID-19. Moreover, the mechanism of COVID-19 shows that some host cell factors, such as an angiotensin-converting enzyme, exhibit daily rhythms. In this review, we explore key findings that show a link between circadian rhythms and viral infection. The results of these findings could be helpful for clinical and preclinical studies to discover a useful and highly effective treatment for eradicating the COVID-19 disease.
\end{abstract}




\section{Highlights}

- The circadian system regulates virtually every aspect of physiological processes.

- There is a bidirectional association between circadian system and immune response.

- Melatonin modulates the immune system and maybe influence COVID-19 healing processes.

- Bmall as one of the main clock genes has an antiviral role in respiratory infections.

- Expression of the ACE-2 gene as the receptor for COVID-19 has circadian rhythmicity

\section{Plain Language Summary}

The body of many animals, including humans behave like a 24-h machine. In mammals, the suprachiasmatic nucleus $(\mathrm{SCN})$ in the hypothalamus acts as an engine for this machine which regulates daily patterns of many different physiological processes such as sleeping and waking, hormone production, blood pressure and higher mental functions. These rhythms are generally called circadian rhythms. The immune system which defends our body against invaders, such as viruses is controlled by the circadian system. Therefore, circadian rhythm can play an important role in the treatment of the new coronavirus by regulating factors related to the body's immune system. These factors require a regular and healthy circadian rhythm to be more effective and any disturbance in the circadian rhythm can lead to disruption in the level of expression and secretion of these factors. It has been shown that various bad habits such as irregularity in the sleep-wake cycle and eating pattern can cause circadian rhythm disturbances. A healthy circadian rhythm can boost resistance to viruses and greatly help human immune system to fight coronaviruses. Therefore, it seems that pay attention to circadian rhythm hygiene is as important as other health tips such as frequently washing hands, using a face mask and gloves. Mandatory quarantine is a good opportunity for people to help improve their circadian rhythm.

\section{Introduction}

$\mathrm{F}$

rom bacteria to humans, almost all living things are exposed to the natural $24 \mathrm{~h}$ light-dark cycle and have an internal clock that regulates most physiological and behavioral processes. Because this internal clock has diurnal fluctuations, it is called circadian rhythms (from the Latin words "circa", meaning "about", and "diem", meaning "day") (Bhadra, Thakkar, Das, \& Pal Bhadra, 2017; Menaker, Moreira, \& Tosini, 1997). A specialized group of photosensitive retinal ganglion cells, so-called melanopsin (ipRGCs), is the first line that received sunlight rays (Duda et al., 2020; Gooley, Chou, Scammell, \& Saper, 2001). Melanopsin transduces light signals into the language of the nervous system, action potential, and then this information reaches the $\mathrm{SCN}$ directly via the retinohypothalamic tract (Coomans, Ramkisoensing, \& Meijer, 2015; Moore, 2013). SCN is the master circadian pacemaker regulating biological processes ranging from subcellular processes, such as gene expression, to behavior (Landgraf, Long, Proulx, Barandas, Malinow, \& Welsh,, 2016; Tso, Simon, Greenlaw, Puri, Mieda, \& Herzog, 2017). It does this through a transcription-translation feedback loop in which proteins stimulate the transcription of other clock proteins and downregulate their transcription (Figure 1). In this way, four families of core clock genes (CLOCK [circadian locomotor output cycles kaput], BMAL1 [brain and muscle ARNT-like1], period [Per], and cryptochrome [Cry]) are rhythmically expressed with a periodicity of about $24 \mathrm{~h}$ (Merrow \& Roenneberg, 2007; Patke, Young, \& Axelrod, 2019; Tauber, Last, Olive, \& Kyriacou, 2004). Although the fluctuation in clock gene expression exists in the cells of extra-SCN brain regions and many other organs, it seems that the phase relationship between the central and peripheral oscillators is adjusted by the SCN (Herzog, Hermanstyne, Smyllie, \& Hastings, 2017; Meijer \& Michel, 2015). CLOCK and BMAL1 play a central role in the clock gene expression feedback loop. CLOCK/BMAL1 dimers, as positive regulators, initiate the expression of Cry and Per genes by binding to enhancer boxes (E-boxes) in their promoter regions. Proteins from these two genes after accumulation and dimerization feedback into the nucleus and by preventing CLOCK/BMAL1 transactivation inhibit their transcription. This is the first feedback loop that is completed over one day. In addition, there is a second feedback loop 
which consists of two sets of nuclear hormone receptors, Rev-erb $\alpha$ (REV-ERBa/b, encoded by Nr1d1/2) and Rora (RAR-related orphan receptor, $\mathrm{RORa} / \mathrm{b}$ ). These two factors compete with each other for binding to the same site, REV ERB/ROR-responsive Elements (RORE) in the regulatory sequence of BMAL1 promoter (Bartman \& Eckle, 2019; Chi-Castaneda \& Ortega, 2017; Matsu-Ura, Moore, \& Hong, 2018). Interestingly, BMAL1 and CLOCK, besides direct transcription of their repressors, i.e. Per and Cry family members, also drive the expression of Clock-Controlled Genes (CCGs), by binding to E-box regulatory element (Chi-Castaneda \& Ortega, 2017). The results of research published so far show that about $43 \%$ of the mammalian genome is expressed rhythmically, so the circadian system through CCGs can regulate different pathways in neural, hormonal metabolism, and even immune functions (Khaksari, Nakhaei, Khastar, Bakhtazad, Rahimi, \& Garmabi, 2020; Koike, Yoo, Huang, Kumar, Lee, Kim, \& Takahashi, 2012). Precise control of physiological processes, such as the immune function, by the internal clock system, alerts the body's immune response to deliver the best response against harmful external factors in appropriate time (Duggal, 2018; Hergenhan, Holtkamp, \& Scheiermann, 2020; Markowska, Majewski, \& Skwarło-Sońta, 2017). Therefore, it is thought that this chronobiological framework is an important property of a healthy hemostatic system. In this regard, it is not surprising that chronodisruption and consequently disturbance in the temporal order of physiological responses can result in detrimental consequences for human health.

\section{Method and Search Strategy}

To fulfill the study objectives, several search strategies were assumed and employed, including electronic databases of PubMed and Medline using title words, keywords, and MeSH terms during the search. There was no limitation for the year of publication. Different combinations of the following terms were used in the search: COVID and Circadian, SARS and circadian, circadian and viral infection, melatonin and viral infection, melatonin and COVID, melatonin and SARS, clock gene and SARS, clock gene and COVID, ACE and COVID, ACE and circadian. The searches were run only among English language studies. All articles were reviewed and conclusions summarized in a narrative review.

\section{Clock Genes and COVID-19 Infections}

Genetic studies performed in animal models have shown that defects in BMAL1 expression, one of the important components of the core clock genes as mentioned above, could be responsible for severely disrupted behavioral cir- cadian rhythms and dampened amplitudes of BMAL1 target genes expression rhythms (Alvarez et al., 2008; Haque, Booreddy, \& Welsh, 2019; Ma et al., 2019; Nakazato et al., 2017). Defects in glucose homeostasis (Harfmann, Schroder, Kachman, Hodge, Zhang, \& Esser, 2016), insulin production (Sadacca, Lamia, deLemos, Blum, \& Weitz, 2011), accelerated aging (Baba et al., 2018) and also increased susceptibility to viral infections (Anderson \& Reiter, 2020; Ehlers et al., 2018) are some of the disorders which have been observed in BMAL1-deficient animals. Ehlers et al. investigated the effect of circadian clock disruption on asthmatic lung phenotypes in a viral model of acute and chronic (Sendai virus [SeV] and influenza A virus in mice) airway disease (Ehlers et al., 2018). They observed that BMAL1-/- mice showed more severe chronic lung disease post-infection, including increased airway resistance and mucus production. They also found altered expression patterns of several clock genes in human airway samples taken from the lungs of patients with asthma.

Similar studies have shown the antiviral role of BMAL1 in infections. It was reported that a reduction in the expression of the BMAL1 transcription factor in the BMAL1-deficient cells is responsible for the increased susceptibility of the animals to infection by two major respiratory viruses of the Paramyxoviridae family, Respiratory Syncytial Virus (RSV) and Parainfluenza Type 3 (PIV3) (Majumdar, Dhar, Patel, Kondratov, \& Barik, 2017). A similar experiment in Immortalized Lung Fibroblasts (ILF) cell culture shows that BMAL1 contributes to the suppression of infectious virus progeny production in the host cells. In this study, immunoblot analysis of viral proteins revealed that replication of both RSV and PIV3 was lower in the control cell lines (BMAL1+/+) compared with the BMAL1-/-. Another study confirmed these findings in two other types of viral infection. The study revealed that the circadian rhythm disturbance group by disrupting BMAL1 demonstrated increased infections in the influenza A and herpes virus. Endoplasmic reticulum function, protein biosynthesis, and intracellular vesicle trafficking are very important pathways that the virus uses for replication in host cells. Interestingly, using proteomics technology to analyze BMAL1-/- and wild type primary cells revealed that the clock regulates all of these pathways (Edgar et al., 2016). In general, all these research achievements indicate that clock genes, especially BMAL1 plays a key role in coordinating the lung anti-inflammatory response to viral infection.

At the end of last year, a new coronavirus (SARSCoV-2) appeared in Wuhan, China. The rapid spread of the virus to various countries due to its high transmission capability as well as severe respiratory morbidity and 
mortality, quickly made it a critical issue in the world (Nadeem et al., 2020; Scavone et al., 2020; Wang et al., 2020). According to the World Health Organization (WHO) situation report, until $4^{\text {th }}$ June 2020, the total global deaths from COVID-19 surpassed 380000. Currently, extensive research on COVID-19 is being conducted around the world. All reports indicate that mild respiratory tract infection is very common among patients and Acute Respiratory Distress Syndrome (ARDS) or severe pneumonia have been reported in $14 \%$ of cases (Chen et al., 2020; Kakodkar, Kaka, \& Baig, 2020; Khoury, Cuenca, Cruz, Figueroa, Rocco, \& Weiss, 2020; Krátká, Luxová, Malíčková, Fürst, \& Šimková, 2020; Lake, 2020).
Because respiratory infections are prominent features of COVID-19 patients, it is possible that the expression of clock genes, including the most important one, BMAL1, has changed dramatically in these patients. Seasonal oscillations in the expression of the BMAL1 gene could be one of the reasons for the rapid spread of novel coronavirus. Because it is documented that in addition to daily fluctuations, the BMAL1 gene also exhibits seasonal variation in humans with the lowest levels detected during the winter months (Dowell, 2001; Kovanen, Saat rikoski, Aromaa, Lönnqvist, \& Partonen, 2010). Given the role of clock genes in the viral infection, evaluating them in COVID patients provides a window to a better understanding of the molecular mechanisms underlying viral infection. In an ongoing experiment, our research

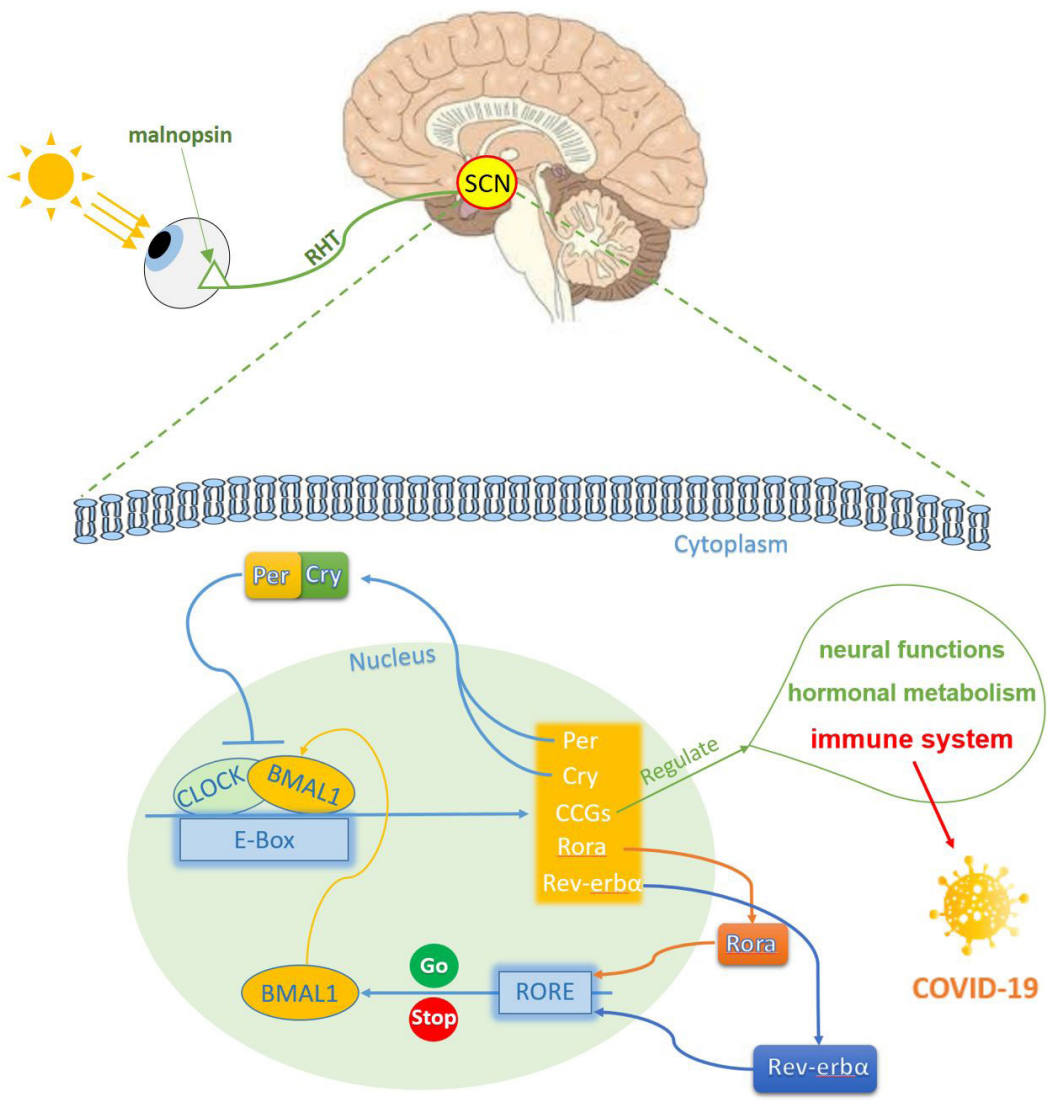

Figure 1. The light signals are first received by melanopsin receptors and then reach the SCN in the hypothalamus via the retinohypothalamic tract

This nucleus controls the circadian rhythm of the whole body by the two cell-autonomous transcription-translation feedback loop which takes approximately a 24-hour cycle to complete. The first feedback loop includes the transcriptional repressors Cryptochrome (Cry) and Period (Per) which inhibit the transcription activators Circadian Locomotor Output Cycles kaput (CLOCK), Brain, and Muscle ARNT-like1 (BMAL1). The second feedback loop consists of two sets of nuclear hormone receptors, Rev-erba and Rora. These two factors compete with each other for binding to the same site, ROREs, in the regulatory sequence of the BMAL1 promoter. Rev-erba and Rora inhibit and induce transcription of the BMAL1 gene, respectively. Clock-controlled genes are involved in the regulation of various cellular pathways in neural, hormonal, and immune functions which its effect on the immune system can play a role in COVID-19 disease. 


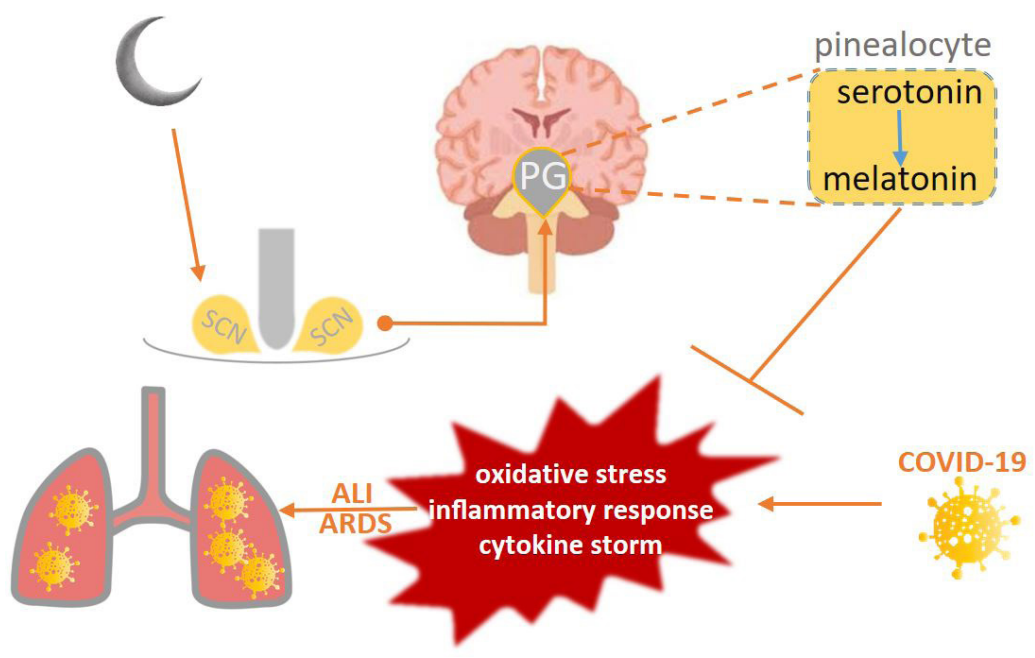

NEUR SCIENCE

Figure 2. Melatonin is synthesized from serotonin in pinealocytes located in the Pineal Gland (PG) during the dark period, in which the signals for the secretion are received from SCN

COVID-19 infections are associated with an increase in oxidative stress, inflammatory response, cytokine storm, and subsequent ALI/ARDS. Investigations show that these effects can be suppressed by melatonin.

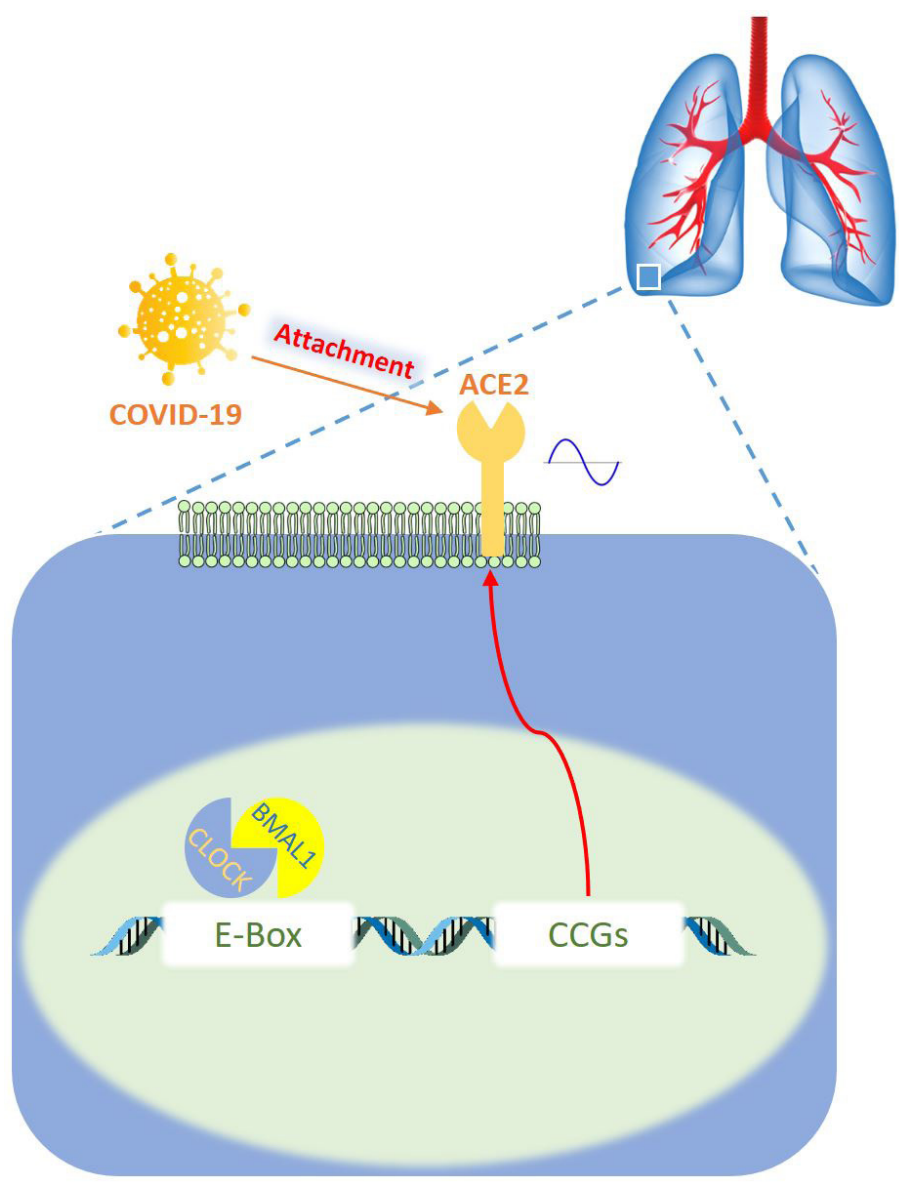

NEUR SCIENCE

Figure 3. Angiotensin-Converting Enzyme 2 (ACE2) is the main host cell receptor of the COVID-19. Research shows that ACE2 is controlled by clock-controlled genes and has circadian rhythmicity 
team is investigating this issue by assessing clock genes expression in the blood of patients with COVID-19.

\section{Melatonin Antiviral Effects}

Melatonin (N-acetyl-5-methoxytryptamine) is one of the most important neurohormones, the secretion of which is strongly under the control of the circadian system and diurnal variation and therefore has a diurnal pattern of release and activity (Amaral \& Cipolla-Neto, 2018; Claustrat \& Leston, 2015; Hardeland, PandiPerumal, \& Cardinali, Esquifino, Srinivasan, \& PandiPerumal, 2006). Melatonin is synthesized in the pineal gland from serotonin during the night by the information it receives from the SCN nucleus via the neural pathway (Figure 2). This hormone is simply secreted from the pineal gland into the cerebrospinal fluid and blood circulation (Arendt, 2005). Extensive research on the melatonin has revealed that the hormone is involved in the regulation of multiple physiological processes either by binding to the G protein-coupled receptors, MT1 and MT2, or interacting directly with intracellular molecules. Melatonin is a biologically active substance with a set of health-promoting features (Habtemariam, Daglia, Sureda, Selamoglu, Gulhan, \& Nabavi, 2017; Hsu Huang, \& Tain, 2019). It is well documented that melatonin can modulate the immune response by regulating the IL-2/ IL-2R system and affecting the production of several cytokines (Cardinali et al., 2008; Carrillo-Vico, Lardone, Alvarez-Sanchez, Rodriguez-Rodriguez, \& Guerrero, 2013; Vinther \& Claesson, 2015). Adjuvant use of melatonin for the treatment of many diseases, including cancer (Ginzac et al., 2020), fibromyalgia (Hemati et al., 2020; Reiter, Acuna-Castroviejo, \& Tan, 2007) and so on have been documented in various studies.

A study on biopsy specimens of lung tissue from two patients with mild COVID-19 revealed edema, multinucleated giant cells, patchy inflammatory cellular infiltration, and proteinaceous exudate with globules (Tian, $\mathrm{Hu}$, Niu, Liu, Xu, \& Xiao, 2020). Besides, autopsy evidence of a COVID-19 patient with Acute Respiratory Distress Syndrome (ARDS) showed pneumocyte desquamation, hyaline membrane formation, and bilateral diffuse alveolar damage with edema (Xu et al., 2020). A growing body of experimental and clinical evidence suggests that the virus stimulates inflammatory responses in the airways (cytokine storm) that causes severe symptoms such as Acute Lung Injury (ALI)/ARDS or even death (Channappanavar \& Perlman, 2017). Analysis of blood samples from COVID-19 patients showed a significant increase in inflammatory factors such as interferon $\gamma$, interleukin $1 \beta$ (IL-1 $\beta)$, monocyte chemoattractant protein
1, interferon-inducible protein 10, and IL-4 and IL-10 (Huang et al., 2020; Wang, Chen, \& Qin, 2020). Blood cell counts in patients admitted to the ICU showed that the immune system is repressed in these patients (Leucopenia, lymphopenia, neutropenia) (Chen et al., 2020). According to the available information, the incidence of inflammation is a prominent feature among COVID-19 patients. Therefore, it can be said that suppressed immune function, excessive inflammation, and subsequent cytokine storm play a major role in the pathogenesis of COVID-19.

Melatonin secretion under the control of circadian rhythm has an indirect anti-viral action. Melatonin is a potent antioxidant and anti-inflammatory (Burchakov \& Uspenskaya, 2017; Favero, Franceschetti, Bonomini, Rodella, \& Rezzani, 2017; Nabavi et al., 2019; Prado, Ferder, Manucha, \& Diez, 2018) hormone which has been proven to play a fundamental role in numerous biological and vital functions, including regulation of apoptosis, optimal mitochondrial function, and stimulating the immune responses (Guo, Jin, Sun, Zhao, Liu, Ma, Sun, \& Yang, 2018; Ozdinc et al., 2016; Reiter Mayo, Tan, Sainz, Alatorre-Jimenez, \& Qin, 2017). In this regard, a study showed that melatonin has an anti-viral effect in mice inoculated with the Semliki Forest Virus (SFV) (Ben-Nathan, Maestroni, Lustig, \& Conti, 1995). In this research, the subcutaneous administration of melatonin profoundly reduced the mortality rate in mice compared with the control group. Natural Killer (NK) cells are a type of cytotoxic lymphocytes that are crucial for the immune system and support rapid reactions to virusinfected cells. A substantial body of evidence in human and animal models indicates that melatonin improves the lytic function of mature NK cells (del Gobbo, Libri, Villani, Calio, \& Nistico, 1989; Lewinski, Zelazowski, Sewerynek, Zerek-Melen, Szkudlinski, \& Zelazowska, 1989; Pires-Lapa, Tamura, Salustiano, \& Markus, 2013). Also, the antioxidative effects of melatonin have been demonstrated in various studies (Adamczyk-Sowa, Pierzchala, Sowa, Polaniak, Kukla, \& Hartel, 2014; Burchakov \& Uspenskaya, 2017). On the one hand, the reduction of pro-oxidative enzymes such as nitric oxide synthase and on the other hand, the increase in antioxidative enzymes such as superoxide dismutase have made melatonin the most powerful endogenous free radical scavenger (Reiter, Ma, \& Sharma, 2020; Wu et al., 2019). Although it may even interact directly with free radicals and act as a free radical scavenger. Thus, these effects support the use of melatonin in COVID-19 infections, which are associated with an increase in oxidative stress, inflammatory response, and cytokine storm. Because of satisfactory safety, melatonin has been tested in 
various clinical trials and the outcomes of the medication have always been beneficial (Andersen, Gogenur, Rosenberg, \& Reiter, 2016; Zisapel, 2015). In short, the melatonin beneficial features consist of multiple actions such as immune surveillance, free radicals scavenging, reducing the molecular destruction, and modulating the processes related to apoptosis. These actions indicate that melatonin should be tested in randomized clinical trials as adjuvant treatment or even as a preventive agent of COVID-19 infections, especially in the elderly community who are vulnerable to the virus and endogenous melatonin secretion have declined in their bodies.

\section{Circadian rhythm in ACE2 and its Role in COVID-19 Disease}

The renin-angiotensin-aldosterone system is a hormonal system that plays a critical role in the regulation of water homeostasis (Ames, Atkins, \& Pitt, 2019; Brewster \& Perazella, 2004; Patel, Rauf, Khan, \& Abu-Izneid, 2017) and blood pressure (Almeida, Tofteng, Madsen, \& Jensen, 2020; Nakagawa, Gomez, Grobe, \& Sigmund, 2020). Renin is released from specialized cells in the kidney in response to a decrease in blood volume, plasma sodium, or blood pressure. Renin cleaves angiotensinogen to angiotensin I (AngI), and subsequently, it is converted to angiotensin II (AngII, a potent vasoconstrictor) by the Angiotensin-Converting Enzyme 1 (ACE1). ACE2 is responsible for the degradation of AngII and binds to the outer cell membrane surface in the heart, arteries, kidney, intestines, and lungs (Perazella \& Setaro, 2003).

Coronavirus studies show many similarities between the COVID-19 virus and original SARS-CoV. To evaluate the risk of novel coronavirus transmission, $\mathrm{Xu}$ et al. performed structural modeling of the COVID-19 spike protein and compared it with the protein in original SARS-CoV (Xu et al., 2020). The authors reported that the three-dimensional structure of the receptor-binding domain of the spike proteins between the two viruses is almost identical. Also, significant commonalities were observed between COVID-19 and SARS-CoV in the sequence of amino acids (with $76.5 \%$ sequence identity). Since the SARS-CoV outbreak, comprehensive structural analyses of the virus have uncovered key atomic-level interactions between the SARS-CoV spike protein receptor-binding domain and its host receptor ACE2 (Bourgonje et al., 2020; Leung et al., 2020; Li et al., 2020; Zhou et al., 2020). The similarity between COVID-19 and SARS-CoV is very important because in vivo and in vitro studies revealed that ACE2 serves as the entry point into cells for SARS-CoV. In other words, it is required for successful entry into the host cell and subsequent viral replication and therefore regulating human-to-human and cross-species transmissions of SARS-CoV (Li et al., 2003). Evidence suggests that the virus entry machinery into the host cell is a major step in the occurrence of the disease. For example, it has been reported that in animals who infected with the SARS$\mathrm{CoV}$, overexpression of human ACE2 has increased the severity of the disease (Yang et al., 2007) or it has been shown that SARS-CoV spike injections into mice exacerbate the lung injury (Imai et al., 2005).

Importantly, this acute lung failure was dependent on ACE2 expression and attenuated by renin-angiotensin system blocking. A recent study by Zhou et al. provided direct evidence of a fundamental role for ACE2 in the COVID-19 disease. By using different species, they demonstrated that overexpression of ACE2 allowed COVID-19 infection and replication and so they precisely identified that SARS-CoV-2 employed ACE2 as a host cellular entry receptor (Zhou et al., 2020). According to the data mentioned above, the attachment of host cell surface ACE2 receptor to the COVID-19 spike protein assists the progress of virus entry and replication.

Many studies have revealed that a majority of circulating parameters, including the renin-angiotensin system show circadian rhythmicity (Cugini \& Lucia, 2004; Gordon, Wolfe, Island, \& Liddle, 1966; Herichova et al., 2007; Kala, Fyhrquist, \& Eisalo, 1973; Portaluppi et al., 1990). The results of investigations show that the levels of plasma renin, aldosterone, and AngII fluctuate with a 24-h rhythm that peaks during the active phase and for the ACE pattern of activity show peaks during the second part of the active phase (Naito et al., 2009). In addition to the circulating RAS, circadian rhythms are also observed in the expression of tissue RAS components (Naito, Tsujino, Fujioka, Ohyanagi, \& Iwasaki, 2002). As mentioned above, the intensity of ACE2 expression is very important in the pathogenesis of COVID-19 disease, and this enzyme is expressed in several tissues, including lung cells (Jia, 2016; Kuba, Imai, Rao, Jiang, \& Penninger, 2006). The results of a study in mice show that the mRNA expression pattern of ACE2 in the aorta has a circadian pattern and its expression decreases during the night (Herichova et al., 2014). However, the rhythm was not observed in the expression of ACE1 in the control group. To the best of our knowledge, no study has yet evaluated how ACE is expressed during the day and night in lung tissue. Nevertheless, there is a possibility that in this tissue, ACE2 is expressed in a circadian pattern, and therefore the time of day of viral infection may influence COVID-19 entry processes and replica- 
tion (Figure 3). The time-of-day effect on viral infection was previously observed by Edgar and colleagues. Their results show that changing the Zeitgeber Time (ZT) affects the extent of virus dissemination and infection. ZT 0 (ZT 0 corresponded to the lights-on time) exhibited 10-fold higher viral replication than ZT 10 (Edgar et al., 2016). Therefore, examining the differences in the risk of becoming infected with the coronavirus at different times of the day can be very helpful for policies related to infection prevention and control, quarantine of individuals, and treatment of COVID-19 disease.

\section{Circadian Rhythm Hygiene}

Life on earth has allowed us to adapt to 24-hour changes, and any factor, such as genetics or epigenetics that disrupts that adaptation, can cost us dearly (Abbott \& Zee, 2019; Rijo-Ferreira \& Takahashi, 2019). It is now becoming clear that disruptions of the circadian rhythm, whether by airline jet lag, night-shift work, or social jet lag (the difference between the social and the biological time zone), are deleterious to human health. Extensive human and animal research shows that dysfunction of the circadian system, whatever the causes, is associated with an increased risk of cardiovascular (Buurma, van Diemen, Thijs, Numans, \& Bonten, 2019; Chellappa et al., 2019) and metabolic diseases (Voigt et al., 2013), diabetes mellitus (Javeed \& Matveyenko, 2018; Onaolapo \& Onaolapo, 2018), depression (Daut \& Fonken, 2019; Mendoza, 2019), addiction (Forde \& Kalsi, 2017; Garme abi, Vousooghi, Vosough, Yoonessi, Bakhtazad, \& Zarrindast, 2016), several cancers (Tsuchiya, Umemura, \& Yagita, 2020) and infectious diseases (Sengupta et al., 2019; Westwood, O’Donnell, de Bekker, Lively, Zuk, \& Reece, , 2019). Many endogen secretory factors that can help the body to cope with viral challenges (such as BMAL1 and melatonin, as indicated above) are controlled by the circadian rhythm. These factors require a regular and healthy circadian rhythm to be more effective and any disturbance in the circadian rhythm can disrupt the level of expression and secretion of these factors. Therefore, a healthy circadian rhythm can boost resistance to viruses and greatly help human immune system to fight coronaviruses. However, the use of smart devices and social networks, the result of our modern lifestyles, have changed sleep behavior. Unfortunately, this change will be exacerbated by quarantine conditions because of no social obligations such as going to work, school or university, and people are free to choose their bedtime and waking hours. Therefore, it seems that paying attention to circadian rhythm hygiene is as important as other health tips such as frequently washing hands, using a facemask and gloves. Isolation and mandatory quarantine is a good opportunity for people to help improve their circadian rhythm by following these tips:

- Sleep and wake time should be set and fairly constant during the quarantine.

- Given that eating time can affect circadian rhythms, there must be a specific plan for mealtime.

- The bedroom should be used only for sleep and sex and it is best not to take smartphones and other smart devices into the bedroom.

- Concurrent with the sunset, try to reduce the intensity of artificial light in the house. At the same time, the night or reading mode option should be activated in all smart devices such as computers and smartphones.

- At least one hour before going to bed, all artificial lights must be turned off. In contrast, try to get more natural light throughout the day.

These suggested guidelines will help people in quarantine adjust their body clock and improves immune system function. Due to the prominent role of the circadian system in maintaining the physiological health of the body, the authors of this manuscript believe that the Circadian Reinforcement Therapy (CRT) (Dunker Svendsen et al., 2019) can also be used as an adjunct treatment for COVID-19 patients who are hospitalized.

\section{Conclusion and Future Direction}

Severe respiratory consequences of the coronavirus disease 2019 pandemic have raised the urgent need for intensive research to better understand the pathophysiology of the disease and development of effective treatment strategies. In this paper, we reviewed the pertinent evidence that suggests a link between circadian rhythms and COVID-19 disease.

The internal circadian system has an important role in maintaining physiological homeostasis and optimal functioning in human life. Research about the importance of the circadian system in viral infections in its infancy not only for the new coronavirus but also for other types of viruses. Therefore, due to the vital role of circadian rhythms in orchestrating all aspects of human physiology and urgent need to unravel precise COVID-19 mechanisms, extensive research should be done in this domain. Further research should focus on the relationship between circadian rhythm disorder and coronavirus 
infection, for example, evaluating the prevalence of COVID-19 in shift workers in cohort studies, the correlation of COVID-19 symptom severity with the level of expression of clock genes, and the relationship between time of day and viral infection in animal models.

The results can help future preventive policies. The use of melatonin and or CRT as adjuvant therapy and considering the time of day when medications are prescribed in clinical trials are under important notions. We expect that considering the above points can pave the way for the use of circadian principles for the prevention and treatment of COVID-19 diseases.

\section{Ethical Considerations}

\section{Funding}

This research did not receive any specific grant from funding agencies in the public, commercial, or not-forprofit sectors.

\section{Authors' contributions}

Conceptualization: Behzad Garmabi; Writing-original draft preparation: Atefeh Bakhtazad, Mehdi Khaksari, and Hosein Khastar; Writing-review and editing: Atefeh Bakhtazad, Behzad Garmabi, Moslem Jafarisani, Reza Jafari, and Majid Salehi; Supervision: Behzad Garmabi.

\section{Conflict of interest}

The author (s) declare that they have no conflict of interest and there has been no financial support for this work that could have influenced its outcome.

\section{References}

Abbott, S. M., \& Zee, P. C. (2019). Circadian Rhythms: Implications for Health and Disease. Neurologic Clinics, 37(3), 601-13. [DOI:10.1016/j.ncl.2019.04.004] [PMID]

Adamczyk-Sowa, M., Pierzchala, K., Sowa, P., Polaniak, R., Kukla, M., \& Hartel, M. (2014). Influence of melatonin supplementation on serum antioxidative properties and impact of the quality of life in multiple sclerosis patients. Journal of Physiology and Pharmacology, 65(4), 543-50.

Almeida, L. F., Tofteng, S. S., Madsen, K., \& Jensen, B. L. (2020) Role of the renin-angiotensin system in kidney development and programming of adult blood pressure. Clinical Science, 134(6), 641-56. [DOI:10.1042/cs20190765] [PMID]

Alvarez, J. D., Hansen, A., Ord, T., Bebas, P., Chappell, P. E., \& Giebultowicz, J. M., et al. (2008). The circadian clock pro- tein BMAL1 is necessary for fertility and proper testosterone production in mice. Journal of Biological Rhythms, 23(1), 26-36. [DOI:10.1177/0748730407311254] [PMID] [PMCID]

Amaral, F. G. D., \& Cipolla-Neto, J. (2018). A brief review about melatonin, a pineal hormone. Archives of Endocrinology and Metabolism, 62(4), 472-9. [DOI:10.20945/2359-3997000000066] [PMID]

Ames, M. K., Atkins, C. E., \& Pitt, B. (2019). The renin-angiotensin-aldosterone system and its suppression. Journal of Veterinary Internal Medicine, 33(2), 363-82. [DOI:10.1111/ jvim.15454] [PMID] [PMCID]

Andersen, L. P., Gogenur, I., Rosenberg, J., \& Reiter, R. J. (2016) The Safety of Melatonin in Humans. Clinical Drug Investigation, 36(3), 169-75. [DOI:10.1007/s40261-015-0368-5] [PMID]

Anderson, G., \& Reiter, R. J. (2020). Melatonin: Roles in influenza, Covid-19, and other viral infections. Reviews in Medical Virology, e2109. [DOI:10.1002/rmv.2109] [PMID] [PMCID]

Arendt, J. (2005). Melatonin: characteristics, concerns, and prospects. Journal of Biological Rhythms, 20(4), 291-303. [DOI:10.1177/0748730405277492] [PMID]

Baba, K., Piano, I., Lyuboslavsky, P., Chrenek, M. A., Sellers, J. T., Zhang, S., et al., (2018). Removal of clock gene Bmal1 from the retina affects retinal development and accelerates cone photoreceptor degeneration during aging. Proceedings of the National Academy of Sciences of the United States of America, 115(51), 13099-104. [DOI:10.1073/pnas.1808137115] [PMID] [PMCID]

Bartman, C. M., \& Eckle, T. (2019). Circadian-Hypoxia Link and its Potential for Treatment of Cardiovascular Disease. Current Pharmaceutical Design, 25(10), 1075-90. [DOI:10.2174/1381612 825666190516081612] [PMID] [PMCID]

Ben-Nathan, D., Maestroni, G. J., Lustig, S., \& Conti, A. (1995) Protective effects of melatonin in mice infected with encephalitis viruses. Archives of Virology, 140(2), 223-30. [DOI:10.1007/ bf01309858] [PMID]

Bhadra, U., Thakkar, N., Das, P., \& Pal Bhadra, M. (2017). Evolution of circadian rhythms: from bacteria to human. Sleep Medicine, 35, 49-61. [DOI:10.1016/j.sleep.2017.04.008] [PMID]

Bourgonje, A. R., Abdulle, A. E., Timens, W., Hillebrands, J. L., Navis, G. J., \& Gordijn, S. J., et al. (2020). Angiotensin-converting Enzyme-2 (ACE2), SARS-CoV-2 and pathophysiology of Coronavirus Disease 2019 (COVID-19). Journal of Pathology. [DOI:10.1002/path.5471] [PMID] [PMCID]

Brewster, U. C., \& Perazella, M. A. (2004). The renin-angiotensinaldosterone system and the kidney: effects on kidney disease. American Journal of Medicine, 116(4), 263-72. [DOI:10.1016/j. amjmed.2003.09.034] [PMID]

Burchakov, D. I., \& Uspenskaya, Y. B. (2017). [Antioxidant, anti-inflammatory and sedative effects of melatonin: results of clinical trials]. Zh Nevrol Psikhiatr Im S S Korsakova, 117(4. Vyp. 2), 67-73.

Buurma, M., van Diemen, J. J. K., Thijs, A., Numans, M. E., \& Bonten, T. N. (2019). Circadian Rhythm of Cardiovascular Disease: The potential of chronotherapy with aspirin. Frontiers in Cardiovascular Medicine, 6, 84. [DOI:10.3389/fcvm.2019.00084] [PMID] [PMCID] 
Cardinali, D. P., Esquifino, A. I., Srinivasan, V., \& Pandi-Perumal, S. R. (2008). Melatonin and the immune system in aging. Neuroimmunomodulation, 15(4-6), 272-8. [DOI:10.1159/000156470] [PMID]

Carrillo-Vico, A., Lardone, P. J., Alvarez-Sanchez, N., RodriguezRodriguez, A., \& Guerrero, J. M. (2013). Melatonin: buffering the immune system. International Journal of Molecular Sciences, 14(4), 8638-83. [DOI:10.3390/ijms14048638] [PMID] [PMCID]

Channappanavar, R., \& Perlman, S. (2017). Pathogenic human coronavirus infections: causes and consequences of cytokine storm and immunopathology. Seminars in Immunopathology, 39(5), 52939. [DOI:10.1007/s00281-017-0629-x] [PMID] [PMCID]

Chellappa, S. L., Vujovic, N., Williams, J. S., \& Scheer, F. (2019). Impact of circadian disruption on cardiovascular function and disease. Trends in Endocrinology \& Metabolism, 30(10), 767-79. [DOI:10.1016/j.tem.2019.07.008] [PMID]

Chen, N., Zhou, M., Dong, X., Qu, J., Gong, F., \& Han, et al. (2020). Epidemiological and clinical characteristics of 99 cases of 2019 novel coronavirus pneumonia in Wuhan, China: a descriptive study. The Lancet, 395(10223), 507-13. [DOI:10.1016/S01406736(20)30211-7]

Chi-Castaneda, D., \& Ortega, A. (2017). The role of mammalian glial cells in circadian rhythm regulation. Neural Plasticity, 2017, 8140737. [DOI:10.1155/2017/8140737] [PMID] [PMCID]

Claustrat, B., \& Leston, J. (2015). Melatonin: Physiological effects in humans. Neurochirurgie, 61(2-3), 77-84. [DOI:10.1016/j.neuchi.2015.03.002] [PMID]

Coomans, C. P., Ramkisoensing, A., \& Meijer, J. H. (2015). The suprachiasmatic nuclei as a seasonal clock. Frontiers in Neuroendocrinology, 37, 29-42. [DOI:10.1016/j.yfrne.2014.11.002] [PMID]

Cugini, P., \& Lucia, P. (2004). [Circadian rhythm of the renin-angiotensin-aldosterone system: A summary of our research studies]. Clinical Therapeutics, 155(7-8), 287-91.

Daut, R. A., \& Fonken, L. K. (2019). Circadian regulation of depression: A role for serotonin. Frontiers in Neuroendocrinology, 54, 100746. [DOI:10.1016/j.yfrne.2019.04.003] [PMID]

del Gobbo, V., Libri, V., Villani, N., Calio, R., \& Nistico, G. (1989). Pinealectomy inhibits interleukin-2 production and natural killer activity in mice. International Immunopharmacology, 11(5), 567-73. [DOI:10.1016/0192-0561(89)90187-2]

Dowell, S. F. (2001). Seasonal variation in host susceptibility and cycles of certain infectious diseases. Emerging Infectious Diseases, 7(3), 369-74. [DOI:10.3201/eid0703.010301] [PMID] [PMCID]

Duda, M., Domagalik, A., Orlowska-Feuer, P., Krzysztynska-Kuleta, O., \& Beldzik, E., et al. (2020). Melanopsin: From a small molecule to brain functions. Neuroscience \& Biobehavioral Reviews, 113, 190203. [DOI:10.1016/j.neubiorev.2020.03.012] [PMID]

Duggal, N. A. (2018). Reversing the immune ageing clock: Lifestyle modifications and pharmacological interventions. Biogerontology, 19(6), 481-96. [DOI:10.1007/s10522-018-9771-7] [PMID] [PMCID]

Dunker Svendsen, S., Aggestrup, A. S., Norregaard, L. B., Loventoft, P., Praestegaard, A., \& Danilenko, K. V., et al. (2019). Circadian reinforcement therapy in combination with electronic self-monitoring to facilitate a safe post-discharge period of patients with depression by stabilizing sleep: protocol of a randomized controlled trial. BMC Psychiatry, 19(1), 124. [DOI:10.1186/s12888-019-2101-z] [PMID] [PMCID]
Edgar, R. S., Stangherlin, A., Nagy, A. D., Nicoll, M. P., Efstathiou, S. \& O'Neill, J. S., et al. (2016). Cell autonomous regulation of herpes and influenza virus infection by the circadian clock. Proceedings of the National Academy of Sciences of the United States of America, 113(36), 10085-90. [DOI:10.1073/pnas.1601895113] [PMID] [PMCID]

Ehlers, A., Xie, W., Agapov, E., Brown, S., Steinberg, D., \& Tidwell, R., et al (2018). BMAL1 links the circadian clock to viral airway pathology and asthma phenotypes. Mucosal Immunology, 11(1), 97111. [DOI:10.1038/mi.2017.24] [PMID] [PMCID]

Favero, G., Franceschetti, L., Bonomini, F., Rodella, L. F., \& Rezzani, R. (2017). Melatonin as an anti-inflammatory agent modulating inflammasome activation. International Journal of Endocrinology, 2017, 1835195. [DOI:10.1155/2017/1835195] [PMID] [PMCID]

Forde, L. A., \& Kalsi, G. (2017). Addiction and the Role of Circadian Genes. Journal of Studies on Alcohol and Drugs, 78(5), 64553. [DOI:10.15288/jsad.2017.78.645] [PMID]

Garmabi, B., Vousooghi, N., Vosough, M., Yoonessi, A., Bakhtazad, A., \& Zarrindast, M. R. (2016). Effect of circadian rhythm disturbance on morphine preference and addiction in male rats: Involvement of period genes and dopamine D1 receptor. Neuroscience, 322, 104-14. [DOI:10.1016/j.neuroscii ence.2016.02.019] [PMID]

Ginzac, A., Dubois, S., Hager, M. O., Kwiatkowski, F., Passildas, J., \& Biau, J., et al. (2020). Quality of life for older patients with cancer: A review of the evidence supporting melatonin use. Aging Clinical and Experimental Research. [DOI:10.1007/ s40520-020-01532-0] [PMID]

Gooley, J. J., Lu, J., Chou, T. C., Scammell, T. E., \& Saper, C. B. (2001). Melanopsin in cells of origin of the retinohypothalamic tract. Nature Neuroscience, 4(12), 1165. [DOI:10.1038/nn768] [PMID]

Gordon, R. D., Wolfe, L. K., Island, D. P., \& Liddle, G. W. (1966). A diurnal rhythm in plasma renin activity in man. Journal of Clinical Investigation, 45(10), 1587-92. [DOI:10.1172/jci105464] [PMID] [PMCID]

Guo, Z. N., Jin, H., Sun, H., Zhao, Y., Liu, J., Ma, H., Sun, X. \& Yang, Y. (2018). Antioxidant melatonin: Potential functions in improving cerebral autoregulation after subarachnoid hemorrhage. Frontiers in Physiology, 9, 1146. [DOI:10.3389/ fphys.2018.01146] [PMID] [PMCID]

Habtemariam, S., Daglia, M., Sureda, A., Selamoglu, Z., Gulhan, M. F., \& Nabavi, S. M. (2017). Melatonin and Respiratory Diseases: A Review. Current Topics in Medicinal Chemistry, 17(4) 467-88. [DOI:10.2174/1568026616666160824120338] [PMID]

Haque, S. N., Booreddy, S. R., \& Welsh, D. K. (2019). Effects of BMAL1 Manipulation on the Brain's Master Circadian Clock and Behavior. Yale Journal of Biology and Medicine, 92(2), 251-258.

Hardeland, R., Pandi-Perumal, S. R., \& Cardinali, D. P. (2006) Melatonin. International Journal of Biochemistry \& Cell Biology, 38(3), 313-6. [DOI:10.1016/j.biocel.2005.08.020] [PMID]

Harfmann, B. D., Schroder, E. A., Kachman, M. T., Hodge, B. A. Zhang, X., \& Esser, K. A. (2016). Muscle-specific loss of Bmal1 leads to disrupted tissue glucose metabolism and systemic glucose homeostasis. Skelet Muscle, 6, 12. [DOI:10.1186/s13395016-0082-x] [PMID] [PMCID] 
Hemati, K., Amini Kadijani, A., Sayehmiri, F., Mehrzadi, S., Zabihiyeganeh, M., Hosseinzadeh, A., \& Mirzaei, A. (2020). Melatonin in the treatment of fibromyalgia symptoms: A systematic review. Complementary Therapies in Clinical Practice, 38, 101072. [DOI:10.1016/j.ctcp.2019.101072] [PMID]

Hergenhan, S., Holtkamp, S., \& Scheiermann, C. (2020). Molecular interactions between components of the circadian clock and the immune system. Journal of Molecular Biology. [DOI:10.1016/j. jmb.2019.12.044] [PMID] [PMCID]

Herichova, I., Mravec, B., Stebelova, K., Krizanova, O., Jurkovicova, D., \& Kvetnansky, R., et al. (2007). Rhythmic clock gene expression in heart, kidney and some brain nuclei involved in blood pressure control in hypertensive TGR(mREN-2)27 rats. Molecular and Cellular Biochemistry, 296(1-2), 25-34. [DOI:10.1007/s11010006-9294-4] [PMID]

Herichova, I., Zsoldosova, K., Vesela, A., \& Zeman, M. (2014) Effect of angiotensin II infusion on rhythmic clock gene expression and local renin-angiotensin system in the aorta of Wistar rats. Endocrine Regulation, 48(3), 144-51. [DOI:10.4149/ endo_2014_03_144] [PMID]

Herzog, E. D., Hermanstyne, T., Smyllie, N. J., \& Hastings, M. H (2017). Regulating the Suprachiasmatic Nucleus (SCN) circadian clockwork: Interplay between cell-autonomous and circuit-level mechanisms. Cold Spring Harbor Perspectives in Biology, 9(1). [DOI:10.1101/cshperspect.a027706] [PMID] [PMCID]

Hsu, C. N., Huang, L. T., \& Tain, Y. L. (2019). Perinatal use of melatonin for offspring health: Focus on cardiovascular and neurological diseases. International Journal of Molecular Sciences, 20(22). [DOI:10.3390/ijms20225681] [PMID] [PMCID]

Huang, C., Wang, Y., Li, X., Ren, L., Zhao, J., \& Hu, Y., et al. (2020). Clinical features of patients infected with 2019 novel coronavirus in Wuhan, China. Lancet, 395(10223), 497-506. [DOI:10.1016/ s0140-6736(20)30183-5]

Imai, Y., Kuba, K., Rao, S., Huan, Y., Guo, F., \& Guan, B., et al. (2005). Angiotensin-converting enzyme 2 protects from severe acute lung failure. Nature, 436(7047), 112-6. [DOI:10.1038/nature03712] [PMID] [PMCID]

Javeed, N., \& Matveyenko, A. V. (2018). Circadian etiology of type 2 diabetes mellitus. Physiology (Bethesda), 33(2), 138-50. [DOI:10.1152/physiol.00003.2018] [PMID] [PMCID]

Jia, H. (2016). Pulmonary Angiotensin-Converting Enzyme 2 (ACE2) and inflammatory lung disease. Shock, 46(3), 239-48. [DOI:10.1097/shk.0000000000000633] [PMID]

Kakodkar, P., Kaka, N., \& Baig, M. N. (2020). A comprehensive literature review on the clinical presentation, and management of the pandemic Coronavirus Disease 2019 (COVID-19). Cureus, 12(4), e7560. [DOI:10.7759/cureus.7560] [PMID] [PMCID]

Kala, R., Fyhrquist, F., \& Eisalo, A. (1973). Diurnal variation of plasma angiotensin II in man. Scandinavian Journal of Clinical and Laboratory Investigation, 31(4), 363-5. [DOI:10.3109/00365517309084318] [PMID]

Khaksari, M., Nakhaei, P., Khastar, H., Bakhtazad, A., Rahimi, K., \& Garmabi, B. (2020). Circadian fluctuation in curiosity is a risk factor for morphine preference. Biological Rhythm Research, 1-13. [DOI:10.1080/09291016.2020.1719682]

Khoury, M., Cuenca, J., Cruz, F. F., Figueroa, F. E., Rocco, P. R M., \& Weiss, D. J. (2020). Current Status of cell-based therapies for respiratory virus infections: Applicability to COVID-19.
European Respiratory Journal. [DOI:10.1183/13993003.008582020] [PMID] [PMCID]

Koike, N., Yoo, S. H., Huang, H. C., Kumar, V., Lee, C., Kim, T. K., \& Takahashi, J. S. (2012). Transcriptional architecture and chromatin landscape of the core circadian clock in mammals. Science, 338(6105), 349-54. [DOI:10.1126/science.1226339] [PMID] [PMCID]

Kovanen, L., Saarikoski, S. T., Aromaa, A., Lönnqvist, J., \& Partonen, T. (2010). ARNTL (BMAL1) and NPAS2 gene variants contribute to fertility and seasonality. PLoS One, 5(4), e10007. [DOI:10.1371/journal.pone.0010007] [PMID] [PMCID]

Krátká, Z., Luxová, Š., Malíčková, K., Fürst, T., \& Šimková, H. (2020). Testing for COVID-19: A few points to remember. Cas Lek Cesk, 159(2), 72-7.

Kuba, K., Imai, Y., Rao, S., Jiang, C., \& Penninger, J. M. (2006). Lessons from SARS: Control of acute lung failure by the SARS receptor ACE2. Journal of Molecular Medicine (Berl), 84(10), 814820. [DOI:10.1007/s00109-006-0094-9] [PMID] [PMCID]

Lake, M. A. (2020). What we know so far: COVID-19 current clinical knowledge and research. Clinical Medicine, 20(2), 124 7. [DOI:10.7861/clinmed.2019-coron] [PMID] [PMCID]

Landgraf, D., Long, J. E., Proulx, C. D., Barandas, R., Malinow, R., \& Welsh, D. K. (2016). Genetic disruption of circadian rhythms in the suprachiasmatic nucleus causes helplessness, behavioral despair, and anxiety-like behavior in mice. Biological Psychiatry, 80(11), 827-35. [DOI:10.1016/j.bił opsych.2016.03.1050] [PMID] [PMCID]

Leung, J. M., Yang, C. X., Tam, A., Shaipanich, T., Hackett, T. L., \& Singhera, G. K., et al. (2020). ACE-2 Expression in the Small Airway Epithelia of Smokers and COPD Patients: Implications for COVID-19. European Respiratory Journal. [DOI:10.1183/13993003.00688-2020] [PMID] [PMCID]

Lewinski, A., Zelazowski, P., Sewerynek, E., Zerek-Melen, G. Szkudlinski, M., \& Zelazowska, E. (1989). Melatonin-induced suppression of human lymphocyte natural killer activity in vitro. Journal of Pineal Research, 7(2), 153-64. [DOI:10.1111/ j.1600-079x.1989.tb00663.x] [PMID]

Li, W., Moore, M. J., Vasilieva, N., Sui, J., Wong, S. K., \& Berne, M. A., et al. (2003). Angiotensin-converting enzyme 2 is a functional receptor for the SARS coronavirus. Nature, 426(6965), 450-4. [DOI:10.1038/nature02145] [PMID] [PMCID]

Li, Y., Zhou, W., Yang, L., \& You, R. (2020). Physiological and pathological regulation of ACE2, the SARS-CoV-2 receptor. Pharmacological Research, 104833. [DOI:10.1016/j. phrs.2020.104833] [PMID] [PMCID]

Ma, Z., Jin, X., Qian, Z., Li, F., Xu, M., \& Zhang, Y., et al. (2019). Deletion of clock gene Bmal1 impaired the chondrocyte function due to disruption of the HIF1a-VEGF signaling pathway. Cell Cycle, 18(13), 1473-89. [DOI:10.1080/15384101.2019.1620 572] [PMID] [PMCID]

Majumdar, T., Dhar, J., Patel, S., Kondratov, R., \& Barik, S. (2017). Circadian transcription factor BMAL1 regulates innate immunity against select RNA viruses. Innate Immunity, 23(2), 147-54. [DOI:10.1177/1753425916681075] [PMID]

Markowska, M., Majewski, P. M., \& Skwarło-Sońta, K. (2017). Avian biological clock - Immune system relationship. Developmental \& Comparative Immunology, 66, 130-8. [DOI:10.1016/j. dci.2016.05.017] [PMID] 
Matsu-Ura, T., Moore, S. R., \& Hong, C. I. (2018). WNT takes two to Tango: Molecular links between the circadian clock and the cell cycle in adult stem cells. Journal of Biological Rhythms, 33(1), 5-14. [DOI:10.1177/0748730417745913] [PMID] [PMCID]

Meijer, J. H., \& Michel, S. (2015). Neurophysiological analysis of the suprachiasmatic nucleus: A challenge at multiple levels. Methods in Enzymology, 552, 75-102. [DOI:10.1016/ bs.mie.2014.11.001] [PMID]

Menaker, M., Moreira, L., \& Tosini, G. (1997). Evolution of circadian organization in vertebrates. Brazilian Journal of Medical and Biological Research, 30, 305-313. [DOI:10.1590/S0100879X1997000300003] [PMID]

Mendoza, J. (2019). Circadian insights into the biology of depression: Symptoms, treatments and animal models. Behavioural Brain Research, 376, 112186. [DOI:10.1016/j.bbr.2019.112186] [PMID]

Merrow, M., \& Roenneberg, T. (2007). Circadian clock: time for a phase shift of ideas? Current Biology, 17(16), R636-638. [DOI:10.1016/j.cub.2007.06.041] [PMID]

Moore, R. Y. (2013). The suprachiasmatic nucleus and the circadian timing system. Progress in Molecular Biology and Translational Science, 119, 1-28. [DOI:10.1016/b978-0-12-3969712.00001-4] [PMID]

Nabavi, S. M., Nabavi, S. F., Sureda, A., Xiao, J., Dehpour, A. R., \& Shirooie, S., et al. (2019). Anti-inflammatory effects of Melatonin: A mechanistic review. Critical Reviews in Food Science and Nutrition, 59(sup1), S4-s16. [DOI:10.1080/10408398.2018. 1487927] [PMID]

Nadeem, M. S., Zamzami, M. A., Choudhry, H., Murtaza, B. N., Kazmi, I., \& Ahmad, H., et al. (2020). Origin, potential therapeutic targets and treatment for Coronavirus Disease (COVID-19). Pathogens, 9(4). [DOI:10.3390/pathogens9040307] [PMID] [PMCID]

Naito, Y., Tsujino, T., Fujioka, Y., Ohyanagi, M., \& Iwasaki, T. (2002). Augmented diurnal variations of the cardiac reninangiotensin system in hypertensive rats. Hypertension, 40(6), 827-33. [DOI:10.1161/01.hyp.0000039960.66987.89] [PMID]

Naito, Y., Tsujino, T., Matsumoto, M., Okuda, S., Sakoda, T., \& Ohyanagi, M., et al. (2009). The mechanism of distinct diurnal variations of renin-angiotensin system in aorta and heart of spontaneously hypertensive rats. Clinical and Experimental Hypertension, 31(8), 625-38. [DOI:10.3109/10641960903406993] [PMID]

Nakagawa, P., Gomez, J., Grobe, J. L., \& Sigmund, C. D. (2020). The renin-angiotensin system in the central nervous system and its role in blood pressure regulation. Current Hypertension Reports, 22(1), 7. [DOI:10.1007/s11906-019-1011-2] [PMID] [PMCID]

Nakazato, R., Kawabe, K., Yamada, D., Ikeno, S., Mieda, M. \& Shimba, S., et al. (2017). Disruption of bmal1 impairs blood-brain barrier integrity via pericyte dysfunction. Journal of Neuroscience, 37(42), 10052-62. [DOI:10.1523/jneuroe sci.3639-16.2017] [PMID] [PMCID]

Onaolapo, A. Y., \& Onaolapo, O. J. (2018). Circadian dysrhythmia-linked diabetes mellitus: Examining melatonin's roles in prophylaxis and management. World Journal of Diabetes, 9(7), 99-114. [DOI:10.4239/wjd.v9.i7.99] [PMID] [PMCID]
Ozdinc, S., Oz, G., Ozdemir, C., Kilic, I., Karakaya, Z., \& Bal, A Koken, T., et al. (2016). Melatonin: is it an effective antioxidant for pulmonary contusion? Journal of Surgical Research, 204(2), 445-51. [DOI:10.1016/j.jss.2016.05.020] [PMID]

Patel, S., Rauf, A., Khan, H., \& Abu-Izneid, T. (2017). ReninAngiotensin-Aldosterone (RAAS): The ubiquitous system for homeostasis and pathologies. Biomedicine \& Pharmacotherapy, 94, 317-25. [DOI:10.1016/j.biopha.2017.07.091] [PMID]

Patke, A., Young, M. W., \& Axelrod, S. (2019). Molecular mechanisms and physiological importance of circadian rhythms. Nature Reviews Molecular Cell Biology. [DOI:10.1038/s41580019-0179-2] [PMID]

Perazella, M. A., \& Setaro, J. F. (2003). Renin-angiotensin-aldosterone system: Fundamental aspects and clinical implications in renal and cardiovascular disorders. Journal of Nuclear Cardiology, 10(2), 184-96. [DOI:10.1067/mnc.2003.392] [PMID]

Pires-Lapa, M. A., Tamura, E. K., Salustiano, E. M., \& Markus, R. P. (2013). Melatonin synthesis in human colostrum mononuclear cells enhances dectin-1-mediated phagocytosis by mononuclear cells. Journal of Pineal Research, 55(3), 240-6. [DOI:10.1111/jpi.12066] [PMID]

Portaluppi, F., Bagni, B., degli Uberti, E., Montanari, L., Cavallini, R., \& Trasforini, G., et al. (1990). Circadian rhythms of atrial natriuretic peptide, renin, aldosterone, cortisol, blood pressure and heart rate in normal and hypertensive subjects. Journal of Hypertension, 8(1), 85-95. [DOI:10.1097/00004872199001000-00013] [PMID]

Prado, N. J., Ferder, L., Manucha, W., \& Diez, E. R. (2018). Antiinflammatory effects of melatonin in obesity and hypertension. Current Hypertension Reports, 20(5), 45. [DOI:10.1007/ s11906-018-0842-6] [PMID]

Reiter, R. J., Acuna-Castroviejo, D., \& Tan, D. X. (2007). Melatonin therapy in fibromyalgia. Current Pain and Headache Reports, 11(5), 339-42. [DOI:10.1007/s11916-007-0215-3] [PMID]

Reiter, R. J., Ma, Q., \& Sharma, R. (2020). Treatment of ebola and other infectious diseases: melatonin "goes viral". Melatonin Research, 3(1), 43-57. [DOI:10.32794/mr11250047]

Reiter, R. J., Mayo, J. C., Tan, D. X., Sainz, R. M., Alatorre-Jimenez, M., \& Qin, L. (2016). Melatonin as an antioxidant: under promises but over delivers. Journal of Pineal Research, 61(3), 253-78. [DOI:10.1111/jpi.12360] [PMID]

Rijo-Ferreira, F., \& Takahashi, J. S. (2019). Genomics of circadian rhythms in health and disease. Genome Medicine, 11(1), 82. [DOI:10.1186/s13073-019-0704-0] [PMID] [PMCID]

Sadacca, L. A., Lamia, K. A., deLemos, A. S., Blum, B., \& Weitz C. J. (2011). An intrinsic circadian clock of the pancreas is required for normal insulin release and glucose homeostasis in mice. Diabetologia, 54(1), 120-4. [DOI:10.1007/s00125-0101920-8] [PMID] [PMCID]

Scavone, C., Brusco, S., Bertini, M., Sportiello, L., Rafaniello, C., \& Zoccoli, A., et al. (2020). Current pharmacological treatments for COVID-19: What's next? British Journal of Pharmacology. [DOI:10.1111/bph.15072] [PMID] [PMCID]

Sengupta, S., Tang, S. Y., Devine, J. C., Anderson, S. T., Nayak, S. \& Zhang, S. L., et al. (2019). Circadian control of lung inflammation in influenza infection. Nature Communications, 10(1) 4107. [DOI:10.1038/s41467-019-11400-9] [PMID] [PMCID] 
Tauber, E., Last, K. S., Olive, P. J., \& Kyriacou, C. (2004). Clock gene evolution and functional divergence. Journal of Biological Rhythms, 19(5), 445-58. [DOI:10.1177/0748730404268775] [PMID]

Tian, S., Hu, W., Niu, L., Liu, H., Xu, H., \& Xiao, S.-Y. (2020). Pulmonary Pathology of Early Phase SARS-COV-2 Pneumonia. [DOI:10.20944/preprints202002.0220.v1]

Tso, C. F., Simon, T., Greenlaw, A. C., Puri, T., Mieda, M., \& Herzog, E. D. (2017). Astrocytes regulate daily rhythms in the suprachiasmatic nucleus and behavior. Journal of Thoracic Onclogy, 27(7), 1055-61. [DOI:10.1016/j.cub.2017.02.037] [PMID] [PMCID]

Tsuchiya, Y., Umemura, Y., \& Yagita, K. (2020). Circadian clock and cancer: From a viewpoint of cellular differentiation. International Journal of Urology. [DOI:10.1111/iju.14231] [PMID]

Vinther, A. G., \& Claesson, M. H. (2015). [The influence of melatonin on the immune system and cancer]. Ugeskrift for Læeger, 177(21), V10140568. [DOI:10.23937/2378-3419/2/4/1024]

Voigt, R. M., Forsyth, C. B., \& Keshavarzian, A. (2013). Circadian disruption: potential implications in inflammatory and metabolic diseases associated with alcohol. Alcohol Research 35(1), 87-96

Wang, H., Li, X., Li, T., Zhang, S., Wang, L., \& Wu, X., et al. (2020). The genetic sequence, origin, and diagnosis of SARS-CoV-2. European Journal of Clinical Microbiology \& Infectious Diseases. [DOI:10.1007/s10096-020-03899-4] [PMID] [PMCID]

Wang, Y., Wang, Y., Chen, Y., \& Qin, Q. (2020). Unique epidemiological and clinical features of the emerging 2019 novel coronavirus pneumonia (COVID-19) implicate special control measures. Journal of Medical Virology. [DOI:10.1002/ jmv.25748] [PMID] [PMCID]

Westwood, M. L., O'Donnell, A. J., de Bekker, C., Lively, C. M., Zuk, M., \& Reece, S. E. (2019). The evolutionary ecology of circadian rhythms in infection. Nature Ecology and Evolution, 3(4), 552-60. [DOI:10.1038/s41559-019-0831-4] [PMID]

Wu, X., Ji, H., Wang, Y., Gu, C., Gu, W., \& Hu, L., et al. (2019). Melatonin alleviates radiation-induced lung injury via regulation of miR-30e/NLRP3 axis. Oxidative Medicine and Cellular Longevity, 2019, 4087298. [DOI:10.1155/2019/4087298] [PMID] [PMCID]

Xu, X., Chen, P., Wang, J., Feng, J., Zhou, H., \& Li, X., et al (2020). Evolution of the novel coronavirus from the ongoing Wuhan outbreak and modeling of its spike protein for risk of human transmission. Science China Life Sciences, 63(3), 457-60. [DOI:10.1007/s11427-020-1637-5] [PMID] [PMCID]

Xu, Z., Shi, L., Wang, Y., Zhang, J., Huang, L., \& Zhang, C., et al. (2020). Pathological findings of COVID-19 associated with acute respiratory distress syndrome. The Lancet Respiratory Medicine. [DOI:10.1016/S2213-2600(20)30076-X]

Yang, X. H., Deng, W., Tong, Z., Liu, Y. X., Zhang, L. F., \& Zhu, H., et al. (2007). Mice transgenic for human angiotensin-converting enzyme 2 provide a model for SARS coronavirus infection. Comparative Medicine, 57(5), 450-9.

Zhou, P., Yang, X. L., Wang, X. G., Hu, B., Zhang, L., \& Zhang, W., et al. (2020). A pneumonia outbreak associated with a new coronavirus of probable bat origin. Nature, 579(7798) 270-273. [DOI:10.1038/s41586-020-2012-7] [PMID] [PMCID]
Zisapel, N. (2015). Safety of melatonin. Journal of Paediatrics and Child Health, 51(8), 840-1. [DOI:10.1111/jpc.12963] [PMID] 
This Page Intentionally Left Blank 